\title{
EFFECTS OF Sr SUBSTITUTION ON CRYSTALLINE STRUCTURE AND RAMAN SPECTRA OF $\mathrm{La}_{2-\mathrm{x}} \mathrm{Sr}_{\mathrm{x}} \mathrm{NiO}_{4+\delta}$
}

\author{
Tran Dang Thanh and Le Van Hong* \\ Institute of Materials Science, VAST, 18 - Hoang Quoc Viet Rd., Hanoi, Vietnam
}

Received 27 December 2007

\begin{abstract}
Effects of $\mathrm{Sr}^{2+}$ substitution for $\mathrm{La}^{3+}$ on oxygen concentration and structure of $\mathrm{La}_{2-\mathrm{x}} \mathrm{Sr}_{\mathrm{x}} \mathrm{NiO}_{4+\delta}$ have been observed by X-ray diffraction and Raman scattering. Oxygen concentration and unit cell volume of the material decrease monotonously in dependence of $\mathrm{x}$. The vibration modes were calculated for $\mathrm{La}_{2} \mathrm{NiO}_{4}$ in $\mathrm{K}_{2} \mathrm{NiF}_{4}$ type structure with the group symmetry of $\mathrm{I} / \mathrm{mmm}$. The Raman active modes for this symmetry were also theoretically identified. Raman back scattering spectra have been carried out for all the ceramic polycrystalline samples at room temperature. Two Raman lines at $224.6 \mathrm{~cm}^{-1}$ and $433 \mathrm{~cm}^{-1}$, assigned to $E_{\mathrm{g}}$ and $\mathrm{A}_{1 \mathrm{~g}}$ vibration modes of oxygen $\mathrm{O}$ (II) in bonding $\mathrm{La} / \mathrm{Sr}-\mathrm{O}$ were observed for all the samples. The lower mode $224.6 \mathrm{~cm}^{-1} \mathrm{shifts}$ down to $208 \mathrm{~cm}^{-1}$, whereas the upper mode $433 \mathrm{~cm}^{-1}$ shifts up when concentration of the $\mathrm{Sr}$ substituting for La increases.
\end{abstract}

Keywords: X-ray diffraction, Perovskite layers, Multiferroic, Raman scattering.

\section{INTRODUCTION}

After the discovery of superconductivity in the La-Ba-Cu-O system by Bednorz and Muller [1], various high- $\mathrm{T}_{\mathrm{c}}$ superconductors have been found. In aim to clarify the mechanism governing in the cuprates, layer structure compounds containing other $3 \mathrm{~d}$ transition metal oxides were investigated. For this purpose, $\mathrm{La}_{2-\mathrm{x}} \mathrm{Sr}_{\mathrm{x}} \mathrm{NiO}_{4}$ has been regarded as a good one among candidates. Crystal structure of $\mathrm{La}_{2} \mathrm{NiO}_{4}$ belongs to the $\mathrm{K}_{2} \mathrm{NiF}_{4}$ type, similar to structure of $\mathrm{La}_{2} \mathrm{CuO}_{4}$ that is a first founded high- $\mathrm{T}_{\mathrm{c}}$ superconductor, containing a single $\mathrm{CuO}_{2}$ layer. Therefore a comprehensive study on structure and properties of $\mathrm{La}_{2-x} \mathrm{Sr}_{x} \mathrm{NiO}_{4}$ in comparison with $\mathrm{La}_{2-}$ ${ }_{\mathrm{x}} \mathrm{Sr}_{\mathrm{x}} \mathrm{CuO}_{4}$ is interested and needed for understanding the superconductivity mechanism in highTc cuprate.

As was reported in [2] the charge and spin ordering have been observed in $\mathrm{La}_{5 / 3} \mathrm{Sr}_{1 / 3} \mathrm{NiO}_{4}$ at the temperature of $\mathrm{T}_{\mathrm{co}} \sim 240 \mathrm{~K}$ and $\mathrm{T}_{\mathrm{so}} \sim 180 \mathrm{~K}$, respectively. Kajimoto et al. [3] reported an observation of rearrangement of the checkerboard charge order to the stripe one in $\mathrm{La}_{1.5} \mathrm{Sr}_{0.5} \mathrm{NiO}_{4}$ by neutron diffraction. Spin state of the $\mathrm{Ni}$ ion has a role in governing the transport and magnetic properties of $\mathrm{La}_{2-\mathrm{x}} \mathrm{Sr}_{\mathrm{x}} \mathrm{NiO}_{4}$ compound, and it depends strongly on the concentration of Sr. As was shown the transition from the high spin to low spin state of Ni ions occurs somewhere with $x$ laying between zero and 1.0 [4]. At room temperature, most authors concluded that the crystal structure of $\mathrm{La}_{2-\mathrm{x}} \mathrm{Sr}_{\mathrm{x}} \mathrm{NiO}_{4}$ system is tetragonal with the symmetry of I4/mmm [5, 11]. Kato et al [7] systematically investigated influences of the substitution of $\mathrm{Sr}$ on structure, unit cell parameters and oxygen deviation in the $\mathrm{La}_{2-\mathrm{x}} \mathrm{Sr}_{\mathrm{x}} \mathrm{NiO}_{4+\delta}$. They also observed

\footnotetext{
* Corresponding author e-mail: honglv@ims.vast.ac.vn
} 
the $\mathrm{I} 4 / \mathrm{mmm}$ tetragonal structure for all the $\mathrm{La}_{2-\mathrm{x}} \mathrm{Sr}_{\mathrm{x}} \mathrm{NiO}_{4+\delta}$ samples. Besides they recorded an increase of valence value of $\mathrm{Ni}$ as well as a change in the lattice parameters a, $\mathrm{c}$ and their ratio c/a at $x$ in a range of $(0.5-0.6)$. However, some other authors described it as the orthorhombic Fmmm [6, 8]. This difference has been explained by a change in structure due to the deviation from the oxygen stoichiometry in $\mathrm{La}_{2-\mathrm{x}} \mathrm{Sr}_{\mathrm{x}} \mathrm{NiO}_{4+\delta}$. Hiroi et al. [6] reported quite recently that the structure of $\mathrm{La}_{2} \mathrm{NiO}_{4+\delta}$ varies with $\delta$, from orthorhombic $(\delta \sim 0.02)$ to tetragonal $(0.04 \leq \delta \leq$ 0.12 ) and subsequently to monoclinic $(\delta \sim 0.2)$. As was shown in [7], the oxygen deviation $\delta$ in the $\mathrm{La}_{2-\mathrm{x}} \mathrm{Sr}_{\mathrm{x}} \mathrm{NiO}_{4+\delta}$ sensitively depends on $\mathrm{x}, \delta$ was equal to $0.14 \pm 0.01$ when $\mathrm{x}=0$ and it decreases rapidly to zero as increasing $x$. As known Raman scattering is a suitable tool for evaluation of the structure of materials, especially in identification of the phonon modes of materials. $\mathrm{La}_{2} \mathrm{NiO}_{4}$ with the tetragonal $\mathrm{K}_{2} \mathrm{NiF}_{4}$-type structure, which has two 4e sites where are located $\mathrm{La}$ and $\mathrm{O}(\mathrm{II})$, in sites $2 \mathrm{a}$ and $4 \mathrm{c}$ are located ion $\mathrm{Ni}$ and $\mathrm{O}(\mathrm{I})$, respectively. Theoretical calculation based on the structure symmetry of $\mathrm{La}_{2} \mathrm{NiO}_{4}$ suggests that among its vibration modes only two $\mathrm{A}_{1 \mathrm{~g}}$ and $2 \mathrm{E}_{\mathrm{g}}$ modes are raman active, and they could be observed in its Raman spectra. Udagawa et al. [14] observed Raman spectra of the $\left(\mathrm{La}_{1-\mathrm{x}} \mathrm{Sr}_{\mathrm{x}}\right)_{2} \mathrm{NiO}_{4}$ with the concentration $\mathrm{x}$ changing in a range of $(0.0-0.4)$ at temperatures of $10,77,300$ and $500 \mathrm{~K}$. They detected two Raman modes at $220 \mathrm{~cm}^{-1}$ and $460 \mathrm{~cm}^{-1}$, which are assigned to an apical-oxygen motion along the a axis with $\mathrm{E}_{\mathrm{g}}$ symmetry and an apical-oxygen motion along the $\mathrm{c}$ axis with $\mathrm{A}_{1 \mathrm{~g}}$ symmetry, respectively. As reported the Raman shift of these two modes exhibits an non-monotonous dependence on the concentration of $\mathrm{Sr}$, and it was explained by the change of the force constants.

In this paper we present the recent results of our research on $\mathrm{La}_{2-\mathrm{x}} \mathrm{Sr}_{\mathrm{x}} \mathrm{NiO}_{4+\delta}$ compound by means of the X-ray diffraction and Raman scattering at room temperature, especially the research was focused on effects of the substitution of $\mathrm{Sr}$ for $\mathrm{La}$ on crystalline structure and phonon modes.

\section{EXPERIMENTAL}

The samples of $\mathrm{La}_{2-\mathrm{x}} \mathrm{Sr}_{\mathrm{x}} \mathrm{NiO}_{4+\delta}$ with $0.0 \leq \mathrm{x} \leq 1.0$ were prepared by a solid state reaction method. Powder of $\mathrm{La}(\mathrm{OH})_{3}, \mathrm{Sr}\left(\mathrm{NO}_{3}\right)_{2}$ and $\mathrm{Ni}\left(\mathrm{CH}_{3} \mathrm{COO}\right)_{2} \cdot 4 \mathrm{H}_{2} \mathrm{O}$ with a purity of $3 \mathrm{~N}$ was used as starting materials. The starting materials were mixed and ground for $4 \mathrm{~h}$ in ethanol and then annealed at a temperature of $500^{\circ} \mathrm{C}$ for $10 \mathrm{~h}$. After that, the samples were mixed and reground again for $4 \mathrm{~h}$ in ethanol. The obtained powder was pressed in pellets with diameter of $13 \mathrm{~mm}$ and height of $0.5 \mathrm{~mm}$. The pellets were annealed at $1100^{\circ} \mathrm{C}$ for $40 \mathrm{~h}$ in air, cooled down to $500^{\circ} \mathrm{C}$ and subsequently annealed at this temperature for $10 \mathrm{~h}$. Finally the samples were cooled down to room temperature with turning off furnace. Phase structure of all the samples was checked by powder X-ray diffraction spectra by means of a SIEMENS D5000 diffract-graph equipped with a $\mathrm{Cu}-\mathrm{k} \alpha$ radiation $(\lambda=1.5406 \AA)$ at room temperature. Based on $\mathrm{X}$ ray diffraction data of the sample of $x=0.0$, crystal structure of the compound has been constructed by means of the crystal modeling method. Using Win-Metric program we have calculated the lattice parameters of structure for all the samples. Raman scattering spectra at room temperature in the energy region between 100 and $1000 \mathrm{~cm}^{-1}$ were recorded by a micro-Raman spectrograph LABRAM-1B equipped with a He-Ne laser $(\lambda=632.817 \mathrm{~nm})$ with a power of $11 \mathrm{~mW}$.

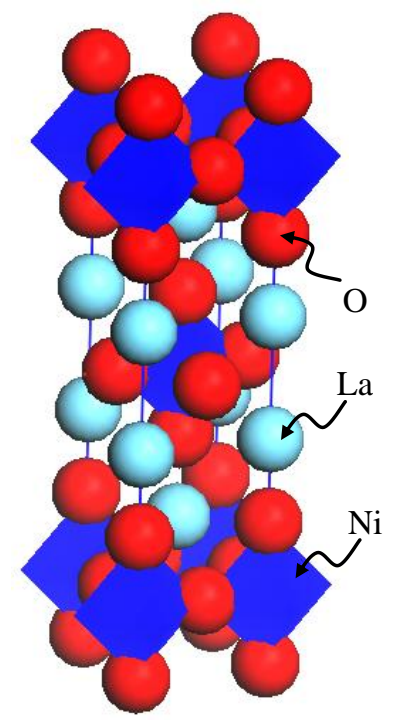

Fig. 1: Unit cell of $\mathrm{La}_{2} \mathrm{NiO}_{4}$ 


\section{RESULTS AND DISCUSSION}

Powder X ray diffraction patterns recorded at room temperature indicate that all the samples are of a single phase with the $\mathrm{K}_{2} \mathrm{NiF}_{4}$ structure. Structure refinement shows that the $\mathrm{La}_{2} \mathrm{NiO}_{4}$ sample has tetragonal structure with the I4/mmm (139) of the space group (Fig. 1). Unit cell of the $\mathrm{La}_{2} \mathrm{NiO}_{4}$ has oxygen in two positions $\mathrm{O}(\mathrm{I})$ and $\mathrm{O}(\mathrm{II})$. The $\mathrm{Ni}$ ion at $(0,0,0)$ sites at position $2 \mathrm{a}$, locating in the center of the $\mathrm{NiO}_{6}$ octahedral. The $\mathrm{La} / \mathrm{Sr}$ and $\mathrm{O}(\mathrm{II})$ ions at $(0,0, \mathrm{z})$ sites, which is noted as $4 \mathrm{e}$ and the $\mathrm{O}(\mathrm{I})$ ions at $(1 / 2,0,0),(0,1 / 2,0)$ sites, which is noted as $4 \mathrm{c}$. At room temperature, all the samples are of the tetragonal. Using the obtained X-ray diffraction powder data, the $a$ and $c$ parameters of unit cell of the samples were calculated by the Win-Metric program. Fig. 2 presents the variations of the lattice parameters and $c / a$ ratio of the $\mathrm{La}_{2-\mathrm{x}} \mathrm{Sr}_{\mathrm{x}} \mathrm{NiO}_{4+\delta}$ samples. The obtained results completely agree with those reported by [7, 11]. It shows a non monotonous dependence in $\mathrm{x}$ with a clear change of $a, c$ parameters, $c / a$ ratio around the values of $x$ equal to 0.5 and 0.6. The a parameter decreases with $x$ below 0.6 and increases for $x$ above, whereas the $c$ parameter increases first with $x$ below 0.5 and decreases for the greater values of $\mathrm{x}$. Consequently the $c / a$ ratio has a maximum value at $x=0.5$. As known the hole doping state established by the $\mathrm{Sr}$ substitution and oxygen excessive plays an important role in magnetic and transport properties of the nikelate. Therefore we have first to check oxygen concentration of the material. The oxygen concentration $(4+\delta)$ of all the samples was determined by using the dicromat method. As known in $[3,4,9,10]$ the replace of $\mathrm{Sr}^{2+}$ for $\mathrm{La}^{3+}$ induces a change of valence of the $\mathrm{Ni}$ from $\mathrm{Ni}^{2+}$ to $\mathrm{Ni}^{3+}$, as a result of the charge neutralization in the material. Concentration of the $\mathrm{Ni}^{2+}$ and $\mathrm{Ni}^{3+}$ could be determined from the previously estimated values $\delta$ by using the principle of charge balance in the $\mathrm{La}_{2}$ ${ }_{\mathrm{x}} \mathrm{Sr}_{\mathrm{x}} \mathrm{NiO}_{4+\delta}$ samples. The determined values of $\delta, \mathrm{Ni}^{2+}$ and $\mathrm{Ni}^{3+}$ for all the $\mathrm{La}_{2-}$ ${ }_{\mathrm{x}} \mathrm{Sr}_{\mathrm{x}} \mathrm{NiO}_{4+\delta}$ samples have been plotted in dependence on $\mathrm{x}$, as presented in figure 3 .

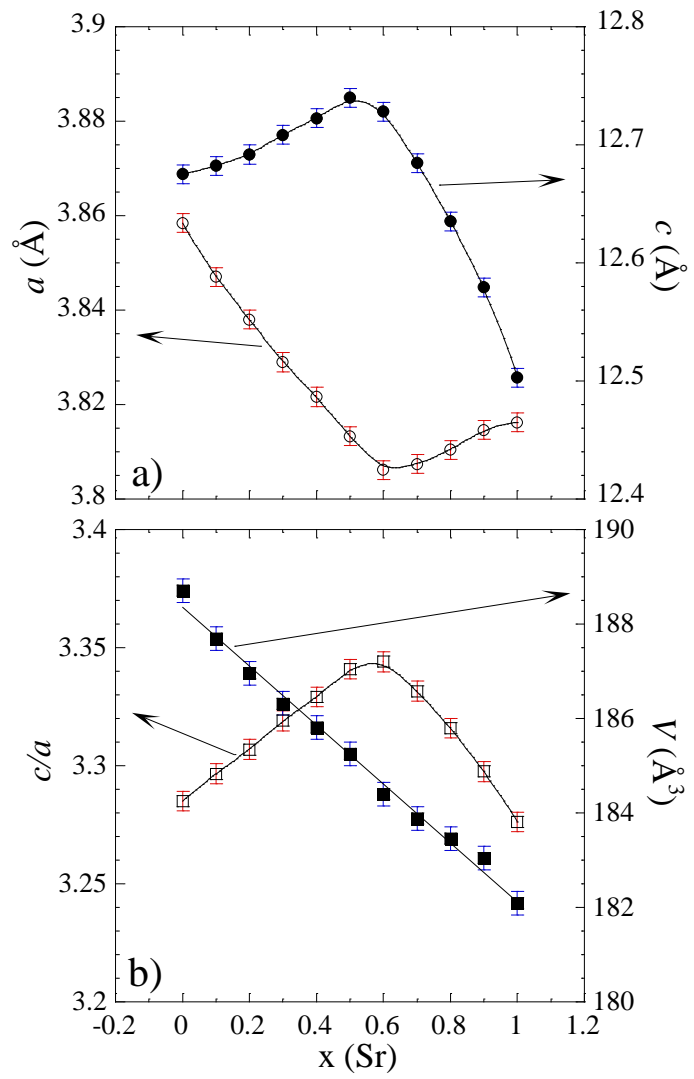

Fig. 2: The lattice constant versus $x(a)$, and the unit cell volume and the ratio c/a versus $x$ (b) of $\mathrm{La}_{2-x} \mathrm{Sr}_{x} \mathrm{NiO}_{4}$.

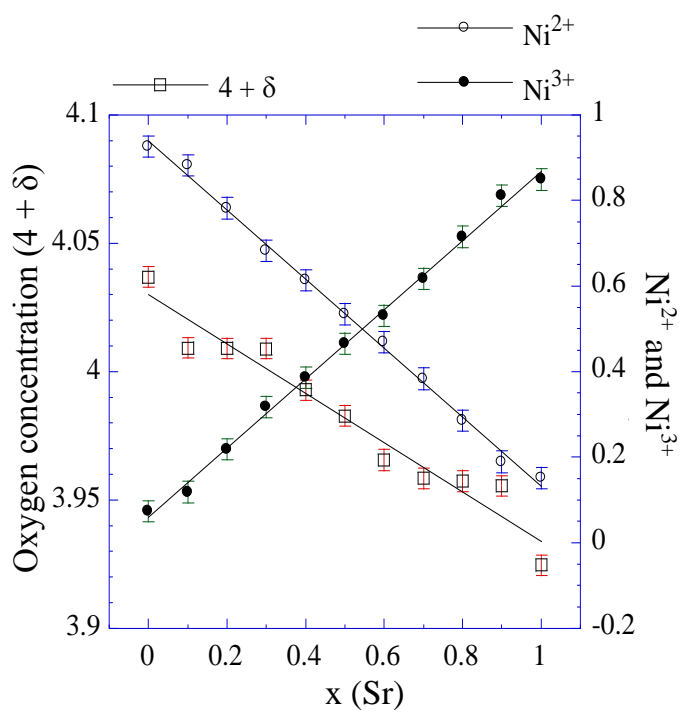

Fig. 3: Dependence of the oxygen, $\mathrm{Ni}^{2+}$ and $\mathrm{Ni}^{3+}$ on $\mathrm{x}$ in $\mathrm{La}_{2-x} \mathrm{Sr}_{x} \mathrm{NiO}_{4+\delta}$ structure. 


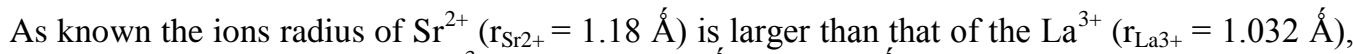
otherwise the ion radius of $\mathrm{Ni}^{3+}\left(\mathrm{r}_{\mathrm{Ni} 3+}=0.56 \AA\right.$ and $0.6 \AA$. with low spin and high spin, respectively) is smaller than that of the $\mathrm{Ni}^{2+}\left(\mathrm{r}_{\mathrm{Ni} 2+}=0.69 \AA\right.$ ) $)$ [12]. Therefore the Sr substitution has a tendency to increase the lattice parameters of $\mathrm{La}_{2-\mathrm{x}} \mathrm{Sr}_{\mathrm{x}} \mathrm{NiO}_{4}$, otherwise as its result, it simultaneously decreases the lattice parameters due to increasing the content of $\mathrm{Ni}^{3+}$, which has smaller ion radius. Consequently we received an nonmonotonous dependence of the $a, c$ and unit cell volume in the dependence on $\mathrm{Sr}$ concentration as presented in Fig. 2. The change of valence value of the $\mathrm{Ni}$ ion in $\mathrm{La}_{2-\mathrm{x}} \mathrm{Sr}_{\mathrm{x}} \mathrm{NiO}_{4}$ and its ion radius in the dependence on $\mathrm{Sr}$ concentration are presented in Fig. 3. It is seen these dependences are linear and cross-cutting each other around the concentration value $\mathrm{x}$ of about 0.5 , where the abnormal change was observed also in the dependence of the lattice parameters and unit cell of the $\mathrm{La}_{2-\mathrm{x}} \mathrm{Sr}_{\mathrm{x}} \mathrm{NiO}_{4}$ on the concentration of $\mathrm{Sr}$ as presented in Fig. 2. We know that the interaction forces between ions and distance between them have most important influences on the phonon modes of materials. In our case the influence of the substitution of $\mathrm{Sr}$ on crystalline structure, the valence of ion $\mathrm{Ni}$, the $\mathrm{La} / \mathrm{Sr}-\mathrm{O}$ and $\mathrm{Ni}-\mathrm{O}$ bond lengths is very complicated, and competitive. As known from group theory, the oxidized $\mathrm{La}_{2-x} \mathrm{Sr}_{\mathrm{x}} \mathrm{NiO}_{4+\delta}$ with I $4 / \mathrm{mmm}_{(}\left(\mathrm{D}_{4 \mathrm{~h}}{ }^{17}\right)$ symmetry has only $2 \mathrm{~A}_{1 \mathrm{~g}}$ and $2 \mathrm{E}_{\mathrm{g}}$ Raman active normal modes at the $\Gamma$ point, because of the $\Gamma^{\text {cry }}=3 \mathrm{~A}_{2 \mathrm{u}}(\mathrm{IR})+4 \mathrm{E}_{\mathrm{u}}(\mathrm{IR})+\mathrm{B}_{2 \mathrm{u}}+2 \mathrm{~A}_{1 \mathrm{~g}}+2$ $\mathrm{E}_{\mathrm{g}}$. The ions $\mathrm{O}(\mathrm{I})$ and $\mathrm{Ni}$ are in the site having center-symmetry, therefore their vibration modes are not Raman active. Only vibration modes of the La and oxygen $\mathrm{O}$ (II) could be Raman active.

Fig. 4 shows Raman spectra of $\mathrm{La}_{2-\mathrm{x}} \mathrm{Sr}_{\mathrm{x}} \mathrm{NiO}_{4}$ recorded at room temperature for $x=0.0-1.0$. Two Raman lines at $220 \mathrm{~cm}^{-1}$ and $430 \mathrm{~cm}^{-1}$ are clearly observed for all the samples. According to the results reported by Maroni et al. [13] and Udagawa et al. [14], we identify the $R_{1}$-Raman line at $220 \mathrm{~cm}^{-1}$ as an apical-oxygen vibration along the $a$ axis with $\mathrm{E}_{\mathrm{g}}$ symmetry and the $\mathrm{R}_{2}$-Raman line at $430 \mathrm{~cm}^{-1}$ as an apical-oxygen vibration along the $c$ axis with $A_{1 g}$ symmetry. As is seen in Fig. 5, the Raman shift of $R_{1}$ and $R_{2}$ exhibits a nonmonotonous dependence on $\mathrm{Sr}$ concentration. Both two modes $R_{1}$ and $R_{2}$ are quite unchanged at the low range of $\mathrm{Sr}$ concentration, subsequently have a clear change at around $\mathrm{x}=0.5, \mathrm{R}_{1}$ slightly decreases, whereas the $R_{2}$ increases as presented in Fig. 5. The value of $x$, where the change in Raman shifts was observed is well coincided to the value

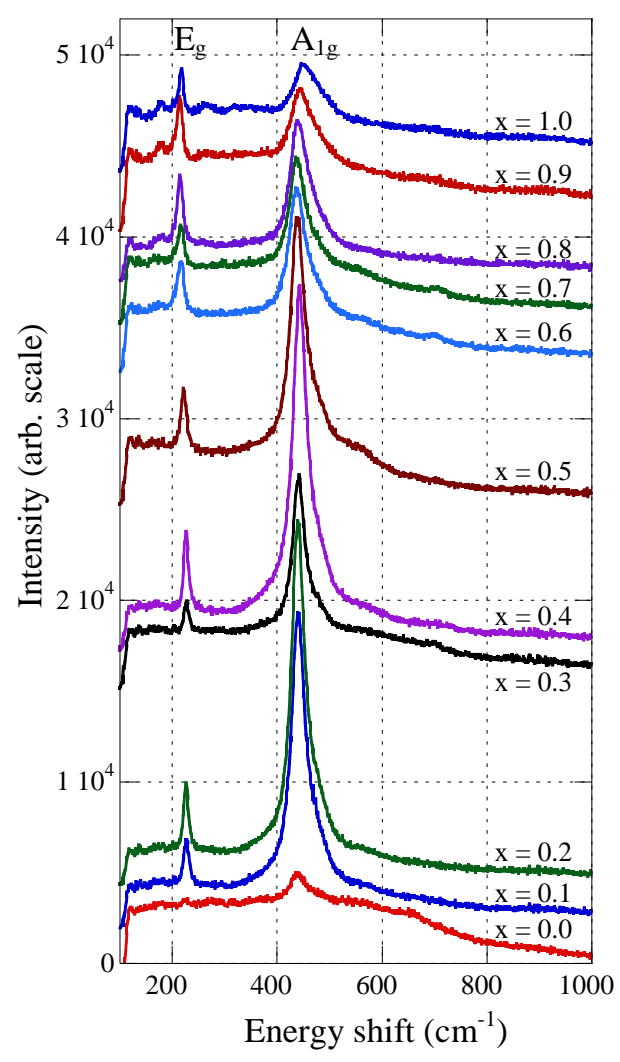

Fig. 4: Raman spectra of $\mathrm{La}_{2-x} \mathrm{Sr}_{x} \mathrm{NiO}_{4}$ recorded at 300K: From bottom to top: $x=0.0-1.0$.

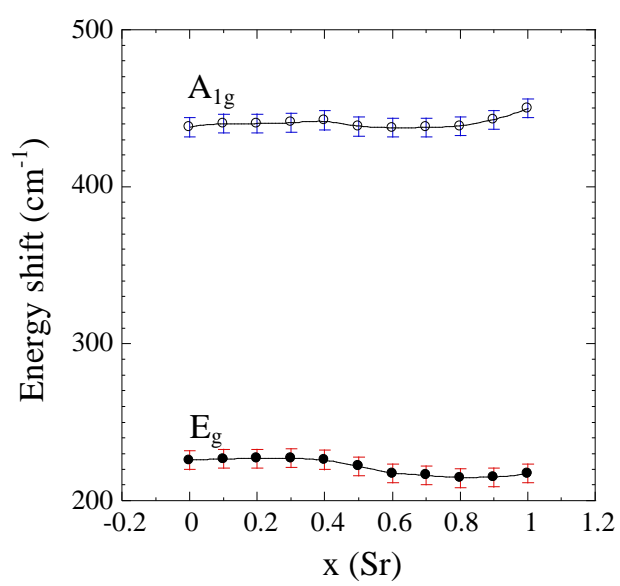

Fig. 5: Raman shift versus $x$ of the $A_{l g}$ and $E_{g}$ modes, measured at room temperature. 
recorded from X-ray diffraction. It reasonably confirms a strong correlation between crystalline structure and Raman scattering in this material. It was known that a change in the bond-length and so on consequently in the force constant, causes a change in the vibration energy of modes, which could be explicitly observed by means of the Raman spectra. Udagawa et al., [14] suggested that the force constant depends on the bond length by an empirical equation as following:

$$
k^{\prime}=k\left(r / r^{\prime}\right)^{n}
$$

Here the $k$, and $k$ ' are force constants for bonds between the same type of atoms having bond length $r$ and $r$ ', respectively, $n$ is a phenomenon parameter, depends on mass and valence of atoms and is about 5-7 in case of $\mathrm{La}_{2-\mathrm{x}} \mathrm{Sr}_{\mathrm{x}} \mathrm{NiO}_{4}$. Upon the results calculated by this equation Udagawa et al. [14] supported that the interaction force between Lanthanum and oxygen ions in $\mathrm{LaO}$ layers plays a strongest affect on the $\mathrm{R}_{1}$ vibration mode. On the $\mathrm{R}_{2}$ vibration mode both two interaction forces in the bonds of Nickel-Oxygen and Lanthanum-Oxygen in $c$ direction are most important factors, which affects on Raman shift of this mode. By using the above principle we qualitatively evaluated the relation between the recorded Raman shift and the concentration of Sr. I was seen that the above principle could used to qualitatively explain Raman spectra of $\mathrm{La}_{2-\mathrm{x}} \mathrm{Sr}_{\mathrm{x}} \mathrm{NiO}_{4}$ in dependence of its hole-doping state, which could be induced by the substitution of $\mathrm{Sr}$ for $\mathrm{La}$ and/or by the excess of oxygen. Besides the two above modes we have also observed a weak line (marked as $\mathrm{R}_{3}$ ) at $\sim 170 \mathrm{~cm}^{-1}$ and a wide band around $700 \mathrm{~cm}^{-1}$. We suppose the first one at $\sim 170 \mathrm{~cm}^{-1}$ is a mode belonging to the $\mathrm{A}_{1 \mathrm{~g}}$ symmetry mode, vibrating in $c$ direction of La. This mode shifts up significantly (more than $10 \mathrm{~cm}^{-1}$ ), and in addition its intensity remarkably increased with the increase of Sr. The wide band may be related with the excess of oxygen and/or Raman activation of the infrared modes of the samples.

\section{CONCLUSION}

By the solid state reaction method, $\mathrm{La}_{2-\mathrm{x}} \mathrm{Sr}_{\mathrm{x}} \mathrm{NiO}_{4+\delta}$ samples $(0.0 \leq x \leq 1.0)$ were successfully prepared. All the samples are of a single phase with $\mathrm{K}_{2} \mathrm{NiF}_{4}$ tetragonal structure. The $\mathrm{Sr}^{2+}$ substitution anomaly affects on $a, c$ parameters and $c / a$ ratio of the $\mathrm{La}_{2-\mathrm{x}} \mathrm{Sr}_{\mathrm{x}} \mathrm{NiO}_{4+\delta}$. The $c / a$ ratio reaches a maximum value at $x$ of about 0.5 . Raman spectra of $\mathrm{La}_{2-\mathrm{x}} \mathrm{Sr}_{x} \mathrm{NiO}_{4+\delta}$ were recorded at room temperature. An $\mathrm{A}_{1 \mathrm{~g}}$ vibration mode of the energy of $220 \mathrm{~cm}^{-1}$ of the apical oxygen $\mathrm{O}$ (II) in the La-O layer, vibrating along the $a$ axis, and an Eg mode of the energy of $430 \mathrm{~cm}^{-1}$ of the apical oxygen in the Ni-O-La chain, vibrating along $c$ axis were recorded. A relation between the $\mathrm{Sr}$ substitution and Raman shift of the apical oxygen in $\mathrm{La}_{2-\mathrm{x}} \mathrm{Sr}_{\mathrm{x}} \mathrm{NiO}_{4+\delta}$ was observed. It was shown that the $\mathrm{Sr}$ substitution complicatedly affects on the crystalline structure and Raman spectra of $\mathrm{La}_{2-\mathrm{x}} \mathrm{Sr}_{\mathrm{x}} \mathrm{NiO}_{4+\delta}$, which could be qualitatively explained by using a relation between the bond length and the interaction force in the La-O layer and La-O-Ni chain in the crystalline structure of $\mathrm{La}_{2-x} \mathrm{Sr}_{x} \mathrm{NiO}_{4+\delta}$. The $\mathrm{Sr}$ substitution with high concentrations could activate a wide band of Raman modes from the Infrared modes and also the a Raman line at $\sim 170 \mathrm{~cm}^{-1}$, which was supposed to be identified as a $\mathrm{A}_{1 \mathrm{~g}}$ vibration mode of La.

\section{ACKNOWLEDGEMENT}

This work was supported in part by the National Fundamental Research Program for Natural Sciences, the Research Project of IMS. The Key Laboratory of Electronic Materials and Devices is acknowledged.

\section{REFERENCES}

1. Bednorz, J.G. and Muller, K.A. (1986), Z. Phys. B 46, 189. 
2. Lee, S.H. and Cheong, S.W. (1997), Phys. Rev. Lett. 79: 2514.

3. Kajimoto, R., Ishizaka, K., Yoshizawa, H., and Tokura, Y. (2003), Phys. Rev. B 67: 014511.

4. Kato, M., Maeno, Y., and Fujita, T. (1991), Phys. C 176, 533.

5. Wu, G., Neumeier, J.J., Ling, C.D., and Argyriou, D.N. (2002), Phys. Rev. B 65, 174113.

6. Hiroi, Z., Obata, T., Takano, M., Bando, Y., Takeda, Y., and Yamamoto, O. (1990), Phys. Rev. B 41, 11665.

7. Kato, M., Maeno, Y., and Fujita, T. (1991), J. Phys. Soc. Japan Vol. 60, No. 6, 1994.

8. Paulus, W., Cousson, A., Dhalenne, G., Berthon, J., Revcolevschi, A., Hosoya, S., Treutmann, W., Heger, G., and Toquin, R.L. (2002), Solid State Sciences 4, 565.

9. Shivakumara, C., Hegde, M.S., Prakash, A.S., Khadar, A.M.A., Subbanna, G.N., and Lalla, N.P. (2003), Solid State Sciences 5, 351.

10. Jung, J.H., Kim, D.W., Noh, T.W., Kim, H.C., Ri, H.C., Levett, S.J., Lees, M.R., Paul, D. McK., and Balakrishnan, G. (2001), Phys. Rev. B 64, 165106.

11. PDF cards, JCPDS-ICDD copyright (2005).

12. Shannon, R.D. (1976), Acta Cryst. A 32, 751.

13. Maroni, V.A., Brun, T.O., Grimsditch, M., and Loong, C.K. (1989), Phys. Rev. B 39, 4127.

14. Udagawa, M., Yamagichi, T., Nagaoka, Y., and Ogita, N. (1993), Phys. Rev. B 47, 17, 11391. 